\title{
Development of a novel social incubator for health promoting initiatives in a disadvantaged region
}

\author{
Sivan Spitzer-Shohat, Jumanah Essa-Hadad ${ }^{*}$ and Mary CJ Rudolf
}

\begin{abstract}
Background: Bottom-up approaches to disparity reduction present a departure from traditional service models where health services are traditionally delivered top-down. Raphael, a novel bottom-up social incubator, was developed in a disadvantaged region with the aim of 'hatching' innovative health improvement interventions through academia-community partnership.
\end{abstract}

Methods: Community organizations were invited to submit proposals for incubation. Selection was made using the criteria of innovation, population neediness and potential for health impact and sustainability. Raphael partnered with organizations to pilot and evaluate their intervention with $\$ 5000$ seed-funding. The evaluation was guided by the conceptual framework of technological incubators. Outcomes and sustainability were ascertained through qualitative and quantitative analysis of records and interviews at 12 months and 3-5 years, and the Community Impact of Research Oriented Partnerships (CIROP) questionnaire was administered to community partners.

Results: Ninety proposals were submitted between 2013 and 2015 principally from non-governmental organizations (NGOs). Thirteen interventions were selected for 'incubation'. Twelve successfully 'hatched': three demonstrated sustainability with extension locally or nationally through acquiring external competitive funding; six continued to have influence within their organizations; three failed to continue beyond the pilot. Benefits to the organisations included acquisition of skills including advocacy, teaching and health promotion, evaluation skills and ability to utilize acquired knowledge for implementation. CIROP demonstrated that individuals' research skills were reported to improve (mean \pm sd) $4.80 \pm 2.49$ along with confidence in being able to use knowledge acquired in everyday practice $(5.50 \pm 1.38)$ and new connections were facilitated (5.33 \pm 2.25$)$.

Conclusions: Raphael, devised as a 'social incubator', succeeded in nurturing novel ideas engendered by community organizations that aimed to impact on health disparities. Judging by success rates of technological incubators its goals were realized to a considerable degree.

Keywords: Health inequity, Social incubator, Community based participatory research

\footnotetext{
* Correspondence: jumanah.essa-hadad@biu.ac.il

Department of Population Health, Azrieli Faculty of Medicine, Bar-llan

University, POB 1589, Henrietta Szold 8, 1311502 Safed, Israel
}

(c) The Author(s). 2020 Open Access This article is licensed under a Creative Commons Attribution 4.0 International License, which permits use, sharing, adaptation, distribution and reproduction in any medium or format, as long as you give appropriate credit to the original author(s) and the source, provide a link to the Creative Commons licence, and indicate if changes were made. The images or other third party material in this article are included in the article's Creative Commons licence, unless indicated otherwise in a credit line to the material. If material is not included in the article's Creative Commons licence and your intended use is not permitted by statutory regulation or exceeds the permitted use, you will need to obtain permission directly from the copyright holder. To view a copy of this licence, visit http://creativecommons.org/licenses/by/4.0/ The Creative Commons Public Domain Dedication waiver (http://creativecommons.org/publicdomain/zero/1.0/) applies to the data made available in this article, unless otherwise stated in a credit line to the data. 


\section{Background}

Health disparities are pervasive and can be identified at all stages of the life cycle, from birth to old age [1]. The widening gaps in both access and provision of care have triggered a search for effective strategies for reducing disparities, generally characterized as either top-tobottom or bottom-up [2,3]. The top-down approach to disparity reduction focuses on health system redesign and the way in which providers can improve health outcomes by improving organisational performance $[4,5]$.

Bottom-up approaches aimed at disparity reduction focus mainly on the tailoring of care processes to the needs of individual patients or specific communities $[2,6]$. These strategies represent a departure from the traditional service model viewing the community simply as recipients of health services, to community engagement in which the community is an active partner in improving health [7-9].

Over the last two decades, one of the most common strategies of community engagement utilized for reducing health disparities is Community Based Participatory Research [10-12]. Community-based participatory research (CBPR) aims at creating transformative research through partnering between academia and the community [13, 14]. In CBPR there is a commitment to feeding back, interpreting, disseminating, and translating the data jointly to create interventions and/or policy which can better the health of the community [15].

Studies report that the formation of such partnerships have been challenging due to the lack of skills and experience of community partners in conducting proper research [16]. Moreover, CBPR partnerships are complex and often encounter barriers such as lack of trust among partners, difficulty in translating from the lab into 'real world', difficulty in changing traditional perceptions on the one-directional flow of knowledge from academia to the community, and difficulty in achieving sustainability [10].

The current paper describes the implementation of Project RAPHAEL, a novel form of CBPR, which was designed as a 'social incubator' for improving health in Israel's disadvantaged northern periphery. The Raphael model draws from the framework of technological incubators and aims to create a supportive environment that is conducive to the "hatching" and development of new interventions to reduce health disparities [17-19]. Over the years, technological incubators have become a ubiquitous phenomenon, creating a platform for academia and business, to promote economic development, innovativeness and the emergence of new technology-based growth firms [20]. Through the combination of practices and professional norms, incubators have been found to promote 'value added ties' in which universities mentor projects, offer access to research facilities as well as gain knowledge on what is happening in the field, while companies gain knowledge skills and scientific credibility [21].

The aim of this paper is to describe the RAPHAEL social incubator model and the extent to which it succeeded not only in fostering and nurturing community-based ideas, but in training and skilling up local organisations so that the intervention formulated had the potential to be sustainable over time.

\section{Methods}

\section{Setting}

The Azrieli Faculty of Medicine was established 7 years ago in the city of Safed in the Galilee, which has among the poorest markers for health and least accessibility to health care in Israel $[22,23]$. Over $37 \%$ of the population lives in poverty, and the majority of towns in the region rate lower than 5 on the national socio-economic 10 step ladder [24]. A significant proportion of the country's most disadvantaged populations live in the Galilee, and are characterized by low income families, low education levels, and high unemployment. The population is diverse comprising communities of ultraorthodox Jews, Ethiopian and Russian immigrants, Druze, and Christian and Muslim Arabs.

\section{Conceptual framework}

Our evaluation was guided by the conceptual framework of technological incubators including: (1) Selection of projects; (2) Support including coaching/training activities undertaken to develop the incubatees, (3) Mediation which refers to the intra-relationships between different projects within the incubators as well as the interrelationships to the outside world, and (4) Graduation/ Hatching which assesses what happens to the projects upon finishing the incubation processes [20].

\section{Phase 1: mapping of submissions}

The first phase of the project involved a call for proposals. This had a dual purpose: to draw in projects for piloting the incubator, and to map health needs from the community perspective. In 2013, 2014 and 2015 a call was disseminated by email, social media, personal contacts and word of mouth to municipalities, NGOs, health maintenance organisations, universities, hospitals, schools, and other community organisations in the region. They were asked to describe the needs of their population and were invited to submit their ideas for a project that they believed would improve health. The call emphasized that the term health was not limited to medical problems and health services.

The submissions received were analysed by the Raphael team considering their focus, the characteristics of the population targeted by the respondents, 
the location of the proposed project and the type of organisation submitting the idea.

\section{Phase 2: selection process}

Applications were independently reviewed by the Raphael team and scored according to the following criteria: creativity and innovation; neediness of the target population; potential impact on health or welfare; potential for sustainability; and potential for replication elsewhere. Proposals of interest were discussed with the Raphael community advisory group, which included stakeholders from the local municipality and regional councils, regional Ministry of Health, and local NGOs. In each cycle 10 to 12 organisations were invited for an in depth interview of which 4 or 5 were selected to participate in the incubator.

\section{Phase 3: mediation - partnership working}

Each of the selected organisations was paired with a coordinator (SS or JE) from the Raphael team whose task was to provide facilitation and academic expertise. This involved helping to ascertain the health needs of the community, finding research evidence to inform the proposed intervention, developing an evaluation framework and accompanying the project during its pilot.

The organisations were brought together every 4 months to engage in dialogue, share experiences, and learn from the know-how and practical experience of each other. They were also provided with $\$ 5000$ in seed funding. On completion of the projects, meetings were held with each organisation to discuss the outcome of the project and help plan for ongoing sustainability.

\section{Phase 4: mixed methodology evaluation}

Organisation representatives completed the Community Impact of Research Oriented Partnerships (CIROP) questionnaire at the end of the incubation period. CIROP is a 33-item tool measuring the extent the partnership improved knowledge and research skill development, organisational development and access/use of information (on a Likert scale of 1-7) [25]. The questionnaire includes 3 open ended questions on major areas of impact; areas of least impact and general comments. Quantitative data was analysed descriptively, and the open-ended questions were analysed for themes.

At the end of the four-year period an overview was carried out by the team assessing the mediation and graduation/hatching of the projects. We assessed the success of the pilot, sustainability in the organisation beyond the end of the project, extension beyond the local organisation, the quality of partnership working and any benefits the coordinator perceived for the organisations. The information was attained from the academic coordinator's detailed notes as well as from key informants, with the organisations where necessary, and underwent an explanatory content analysis.

Telephone interviews were also conducted in January 2019 to ascertain the extent to which projects had been sustained and whether they were ongoing in any form within or beyond the organisation. A member check [26] was also conducted to receive their feedback on the Raphael overview.

Finally, three researchers reviewed the projects independently using a 5-point scale to score the projects' implementation: 1 - extended beyond the base site / 2 - sustained locally / 3 - incompletely sustained but some ongoing influence / 4 - not sustained / 5 - failure to implement. The ratings were discussed until interrater reliability was attained.

\section{Results}

Mapping of submissions

A total of 90 applications were received between 2013 and 2015. Table 1 shows the focus of the proposals, their target populations, the type of organisation and proximity to the medical school. Organisations responding to the call were for the most part NGOs from across the Region, although local municipalities also featured; there was surprisingly little response from the health sector. Almost half the proposals focused on lifestyle and improving well-being. The remainder related to long term medical conditions and preventive medicine with a minority addressing health services and the environment.

\section{Selection for participation in the social incubator}

Over the course of 3 cycles, 13 proposals were selected to participate in Raphael (see Table 1). Over half related to mental health or illness, and targeted both Jewish and Arab populations. The community advisory board proved to be invaluable, particularly regarding the local knowledge they provided about the submitting organisations. Table 2 provides details of the selected partners, the projects and the innovative aspects that influenced their selection.

\section{Partnership working}

Good partnership working was achieved with all 13 partners, although geographic distance from the Raphael team proved a challenge. The Raphael team primarily took a supportive role, with development of the evaluation process being a significant contribution in all cases. All but one of the projects completed their proposed project, although for most the duration extended beyond the 'incubation period' of 12 months.

A total of seven network meetings were implemented at the Faculty over the course of the first 2 cycles. The meetings involved bringing partners together to share their activities with the others, as well as capacity 
Table 1 Analysis of 90 proposals submitted to the social incubator

\begin{tabular}{|c|c|c|}
\hline & $\begin{array}{l}\text { Submitted proposals } \\
n=90\end{array}$ & $\begin{array}{l}\text { Selected proposals } \\
n=13\end{array}$ \\
\hline \multicolumn{3}{|l|}{ Primary focus of the project } \\
\hline Lifestyle & $21(23 \%)$ & 1 \\
\hline Well-being/mental health & $16(18 \%)$ & 3 \\
\hline Mental illness & $12(13 \%)$ & 4 \\
\hline Disability & $11(12 \%)$ & 2 \\
\hline Preventive medicine (screening, child injury prevention, infectious diseases) & $9(10 \%)$ & 2 \\
\hline Chronic illness (including cancer) & $6(7 \%)$ & - \\
\hline Sexual abuse and violence & $6(7 \%)$ & - \\
\hline Health services quality improvement & $6(7 \%)$ & - \\
\hline Environmental issues & $3(3 \%)$ & 1 \\
\hline \multicolumn{3}{|l|}{ Ethnicity of target population } \\
\hline Jewish & $33(37 \%)$ & 5 \\
\hline Arab & $25(28 \%)$ & 3 \\
\hline Haredi & $3(3 \%)$ & 1 \\
\hline Mixed Jewish Arab & $29(32 \%)$ & 4 \\
\hline \multicolumn{3}{|l|}{ Submitting organisation ${ }^{a}$} \\
\hline NGO & $56(59 \%)$ & 6 \\
\hline Local municipality & $14(15 \%)$ & 5 \\
\hline Hospital & $11(11 \%)$ & 1 \\
\hline University & $6(6 \%)$ & - \\
\hline Private initiatives & $5(5 \%)$ & - \\
\hline $\mathrm{HMO}$ & $2(2 \%)$ & - \\
\hline School & $2(2 \%)$ & 1 \\
\hline \multicolumn{3}{|l|}{ Proximity to the medical school ${ }^{a}$} \\
\hline Local to Safed & $23(24 \%)$ & 8 \\
\hline Within $30 \mathrm{~km}$ radius of Safed & $6(6 \%)$ & 1 \\
\hline More than $30 \mathrm{~km}$ radius of Safed & 67 (70\%) & 5 \\
\hline
\end{tabular}

${ }^{\mathrm{a}}$ Total $>90$ as some projects were submitted by 2 collaborating organisations

building sessions on organisational development, using communication for disseminating the project, resource development, and project evaluation. These were well attended by local organisations but less so by organisations located outside of Safed. In the third cycle it was evident that partners were struggling to attend due to their geographical distance from the Faculty and so the meetings were discontinued.

\section{CIROP results}

The CIROP questionnaire revealed that although personal research skills only somewhat improved $(\mathrm{x}=$ $4.80 \mathrm{sd}=2.49$ ), organisations' felt that the program increased their confidence in being able to use the knowledge acquired in everyday practice $(x=5.50 \mathrm{sd}=$ 1.38), and facilitated in formation of new connections $(x=5.33, \mathrm{sd}=2.25)$.

\section{Qualitative analysis of the overview}

The call for proposals achieved its end, with the quantity and richness of the proposals providing a form of mapping of the broad range of concerns and work done by local NGO's, focused on the needy across all age ranges from both Arab and Jewish communities. The selection process was challenging, and the community advisory board engendered community liaison, which in itself was positive for a young medical school.

All but one project was implemented. All 12 implemented projects were successful in the short term at least, and nine went on to maintain aspects of the project; three of the projects can be considered truly 'hatched'; they have received grants from external competitive funding sources and have extended their projects locally and even nationally. Details of the projects, their outcomes and success in the long term (along with their scores on the 5-point scale) are provided in Table 2. 


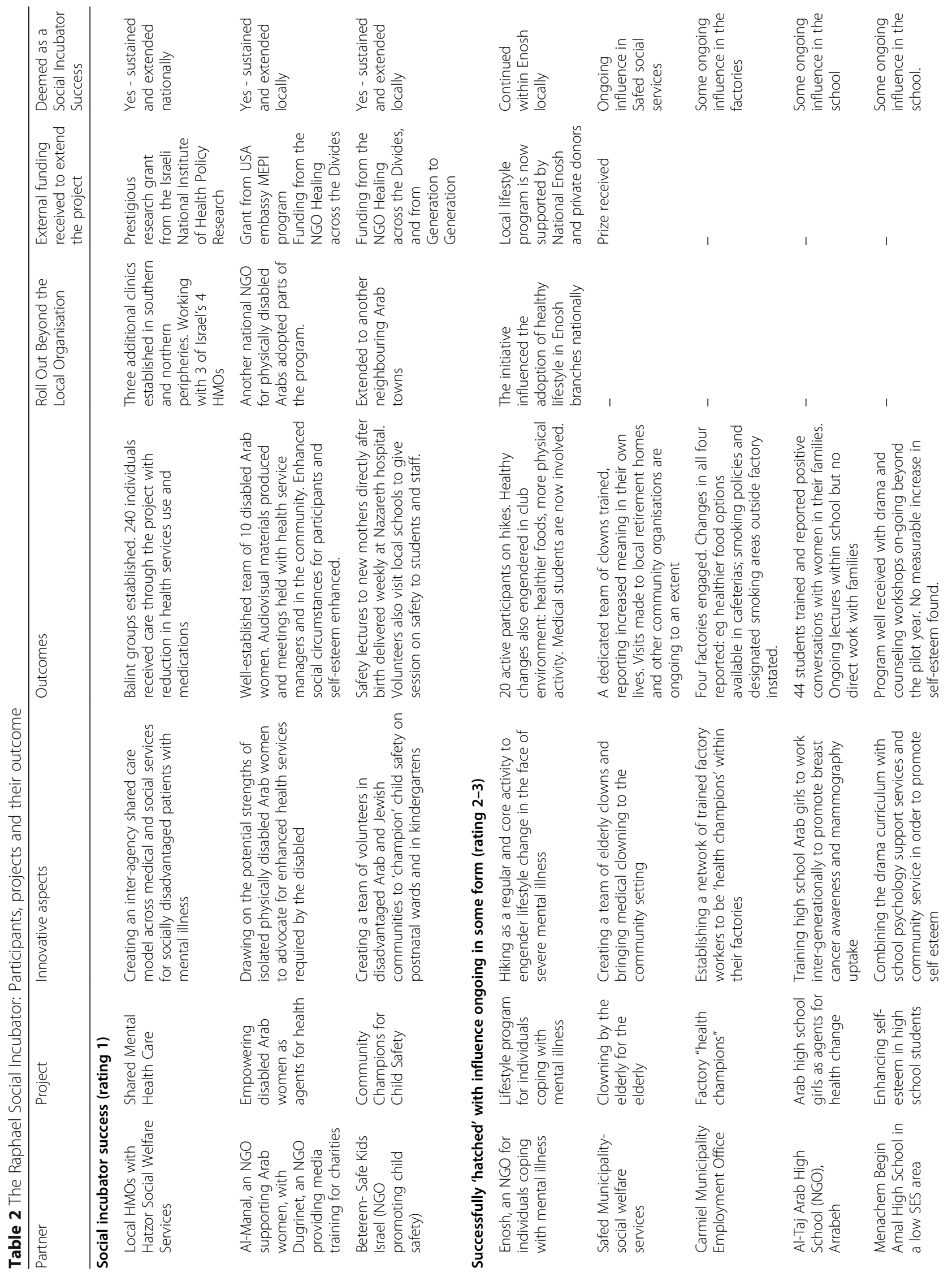




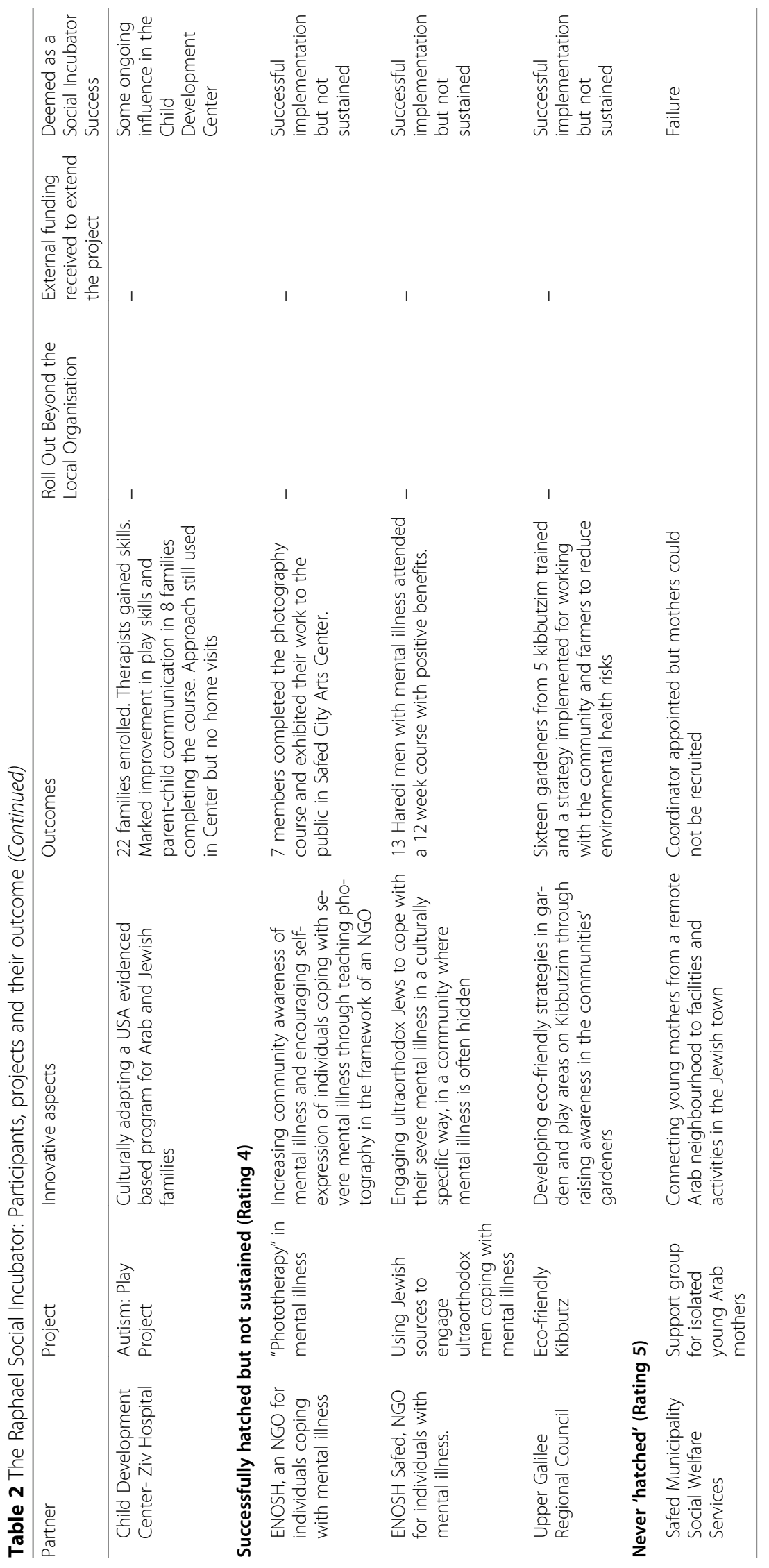


Qualitative analysis revealed a variance in priorities with organisations focusing on practicality and implementation with less emphasis on rigorous evaluation. In the words of one manager: "NGOs usually work with funding bodies that demand reports, not research. Research sometimes is the need of the academic partner and does not answer to the needs of the project directly." (Manager, Org. 1).

Indeed, the focus of the projects proved to be less on research than anticipated, although the evaluation process was central in a number of ways. It generated a greater focus by the community partners on what they were hoping to achieve, it assisted in giving credibility to the project and the community partner and allowed both partners to appreciate the success of the outcome.

A significant success of the partnership was the impact that participation in Raphael had on training of partners' staff, members and volunteers with skills such as advocacy, teaching, therapeutic approaches or health promotion. It was assumed that partnership working with an academic team would also engender capacity building in the organisations, however, there was little evidence that staff were using more generic skills to develop their organisations. The four monthly meetings of the group were initially a success but were discontinued in the third cycle as only local organisations managed to attend. It was very evident that in almost every case a longer time-frame and more resources were required to extend projects beyond their immediate local organisation.

\section{Discussion}

This paper describes an attempt by a medical school to adapt the technological incubator model and use it to develop and 'hatch' novel community interventions with the potential to promote health, in sectors where health disparities are most apparent. The approach can be considered a form of CBPR in its aim to develop community partnerships and foster innovative interventions to improve health [15]. However Project Raphael differed in its scope, in that it worked broadly with a number of organisations, who had generated their own ideas. The organisations had full ownership, while the medical school took more of a supportive role, and the focus was less on research, although a rigorous evaluation process was developed for each project.

There are a number of levels by which one can judge whether this novel incubator was a success. Of the 13 participating projects all but one was implemented. Three subsequently showed real proof of concept, demonstrated by community partners' attaining ongoing competitive funding from national and international sources. Their innovative low-cost ideas targeting disadvantaged populations did not only help secure funding, but were the main facilitator in sustaining these projects over time.

Unlike technological incubators, a social incubator is not likely to create a platform for academia and business, nor promote the emergence of new technologybased growth firms [27], however it was clear that 'value added ties' [20, 21] were promoted. The Medical Faculty mentored the projects and contributed knowledge on what was happening in the field at large, while gaining an understanding of current local efforts at the grassroots level. Community partners gained knowledge, skills and credibility and the opportunity to develop, launch and implement innovative projects. These ties were not limited to the three projects that successfully hatched; all of the projects benefited and were sustained to different extents in their own settings.

The concept of a social incubator should be viewed in the context of CBPR. Wallerstein and Duran (2010) [28], described the challenges of CBPR partnerships, which included common barriers of lack of trust, difficulty in changing traditional perceptions, uni-directional flow of knowledge from academia to the community and difficulty in achieving sustainability. Our experience with Raphael indicated that trust was readily achieved and knowledge exchange between the partners was certainly bi-directional. Sustainability inevitably proved to be a challenge but, as discussed, we were well satisfied by the degree of sustainability that was attained.

The overarching aim of Raphael was to contribute to health by providing solutions that had the potential to reduce disparities across the Region. It was gratifying that the first step of partnering with appropriate organisations was reached; incubator partnerships were established with non-profit organisations working with disadvantaged and harder to reach local populations, particularly Arab and ultra-orthodox (Haredi) communities, the disabled and those suffering from mental illness. As hoped, the application process with 90 responses allowed preliminary mapping of the health concerns that preoccupy community organisations. It seemed more than appropriate that so many projects focused on lifestyle and emotional wellbeing, given the widespread problems of non-communicable diseases and mental illness, which differentially afflict the poor and disadvantaged.

Two of the incubator's aims were less adequately fulfilled. The attempt to foster a network of health promoting organisations with the medical school at the hub failed, principally because distances mitigated against meeting, even periodically, to share ideas and progress. Our assumption that partnership working with an academic team would engender capacity building in the partner organisations was also not realised. While most of the projects involved specific training relating to the 
project aims within the organisations, there was less evidence that staff were using more generic skills to develop their organisations.

On a final note, there was an additional benefit that is worthy of mention. The medical school was less than a year old when Project Raphael was conceived. With a strong focus on medical education and development of laboratory based medical science, it was already in danger of becoming a remote ivory tower on the hill. There is no doubt that Project Raphael averted this and successfully opened the medical school's doors to the local community and engendered meaningful connections which have borne fruit.

\section{Conclusions}

Project Raphael was devised as a 'social incubator' adapting the concept of technological incubators [21] as its model. It aimed to tackle health disparities in a disadvantaged region by adopting a 'bottom up' approach [2] and nurturing novel ideas engendered by community organisations. Judging the experiment in the light of technological incubators it was a success, in the short term at least. Using Rothschild and Darr's criteria for technological incubators [21], Project Raphael led to a combination of practices and professional norms, promoted 'value added ties' in which the medical school took a mentoring role, offered access to academic expertise and knowledge on what was happening in the field, and led to a gain in knowledge, skills and credibility within the organisations.

\footnotetext{
LESSONS LEARNT

- The concept of a 'social incubator' is a feasible and novel way to create productive academia-community partnerships while demanding minimal resources.

- The process led community partners to develop stronger

connections with key stakeholders such as municipalities, other NGOs, and local government offices.

- The diversity of the population, organisations and locations enriched the process and mutual knowledge of local needs.

- A strength of the academic team was its multidisciplinary nature, knowledge of the area and culture, and local languages.

- The time frame required is greater than 12 months for adequate design and implement of projects.

- The partnership needs to address scalability as well as sustainability.

- The process embedded the Faculty in the community and created a platform for its social accountability.
}

\section{Abbreviations}

NGO: Non-governmental organization; CBPR: Community Based Participatory Research; CIROP: Community Impact of Research Oriented Partnerships

\section{Acknowledgements}

Not applicable.

\section{Authors' contributions}

SS and MR prepared the draft of the manuscript. JS conducted the interviews. JS and SS analyzed the data. All authors read and approved the final manuscript.

\section{Funding}

Funding was received from the United Jewish Israel Appeal (UJIA) to support implementation of the community organization projects.

\section{Availability of data and materials}

Not applicable.

\section{Ethics approval and consent to participate}

According to the Bar llan University ethics requirements, the study received an exemption from ethics approval.

\section{Consent for publication}

Not applicable.

\section{Competing interests}

The authors declare that they have no competing interests.

Received: 17 April 2019 Accepted: 27 May 2020

Published online: 10 June 2020

\section{References}

1. Marmot M, Allen JJ. Social determinants of health equity. Am J Public Health. 2014;104(S4):517-9. https://doi.org/10.2105/AJPH.2014.302200.

2. Franks $P$, Fiscella K. Reducing disparities downstream: prospects and challenges. J Gen Intern Med. 2008;23(5):672-7. https://doi.org/10.1007/ s11606-008-0509-0.

3. Clarke AR, Goddu AP, Nocon RS, et al. Thirty years of disparities intervention research: what are we doing to close racial and ethnic gaps in health care? Med Care. 2013;51(11):1020-6. https://doi.org/10.1097/MLR. Ob013e3182a97ba3.

4. Peek ME, Wilson SC, Bussey-Jones J, et al. A study of national physician organizations' efforts to reduce racial and ethnic health disparities in the United States. Acad Med. 2012;87(6):694-700. https://doi.org/10.1097/ACM 0b013e318253b074.

5. Chin MH, Clarke AR, Nocon RS, et al. A roadmap and best practices for organizations to reduce racial and ethnic disparities in health care. J Gen Intern Med. 2012;27(8):992-1000. https://doi.org/10.1007/s11606-012-2082-9.

6. Anderson LM, Adeney KL, Shinn C, Safranek S, Buckner-Brown J, Krause LK. Community coalition-driven interventions to reduce health disparities among racial and ethnic minority populations. Cochrane Database Syst Rev. 2015;6. https://doi.org/10.1002/14651858.CD009905.pub2.

7. Wilkes AE, Bordenave K, Vinci L, Peek ME. Addressing diabetes racial and ethnic disparities: lessons learned from quality improvement collaboratives. Diabetes Manag. 2011;1(6):653-60. https://doi.org/10.2217/dmt.11.48.

8. Prezio EA, Cheng D, Balasubramanian BA, Shuval K, Kendzor DE, Culica D. Community diabetes education (CoDE) for uninsured Mexican Americans: A randomized controlled trial of a culturally tailored diabetes education and management program led by a community health worker. Diabetes Res Clin Pract. 2013;100(1):19-28. https://doi.org/10.1016/j.diabres.2013.01.027.

9. Anderson LM, Adeney KL, Shinn C, Safranek S, Buckner-Brown J, Krause LK. Community coalition-driven interventions to reduce health disparities among racial and ethnic minority populations. Cochrane Database Syst Rev. 2015;6 N.PAG-N.PAG. http://proxy.uchicago.edu/login?url=http://search. ebscohost.com/login.aspx?direct=true \&db=rzh\&AN=109840234\&site=ehostlive\&scope =site.

10. Hicks S, Duran B, Wallerstein N, et al. Evaluating community-based participatory research to improve community-partnered science and community health. Prog Community Health Partnersh. 2012;6(3):289-99. https://doi.org/10.1353/cpr.2012.0049.

11. Cacari-Stone L, Wallerstein N, Garcia AP, Minkler M. The promise of community-based participatory research for health equity: a conceptual model for bridging evidence with policy. Am J Public Health. 2014;104(9): 1615-23. https://doi.org/10.2105/AJPH.2014.301961.

12. Ward M, Schulz AJ, Israel BA, Rice K, Martenies SE, Markarian E. A conceptual framework for evaluating health equity promotion within community-based participatory research partnerships. Eval Program Plan. 2018;70:25-34. https://doi.org/10.1016/J.EVALPROGPLAN.2018.04.014.

13. Coombe CM, Schulz AJ, Guluma L, et al. Enhancing capacity of communityacademic partnerships to achieve health equity: results from the CBPR partnership academy. Health Promot Pract. 2018;152483991881883. https:// doi.org/10.1177/1524839918818830. 
14. Sandoval JA, Lucero J, Oetzel J, et al. Process and outcome constructs for evaluating community-based participatory research projects: a matrix of existing measures. Health Educ Res. 2012;27(4):680-90. https://doi.org/10. 1093/her/cyr087.

15. Israel BA, Parker EA, Rowe Z, et al. Community-based participatory research: lessons learned from the centers for Children's environmental health and disease prevention research. Environ Health Perspect. 2005;113(10):1463-71 http://www.pubmedcentral.nih.gov/articlerender.fcgi?artid=1281296\&tool= pmcentrez\&rendertype=abstract. Accessed 28 Jan 2016.

16. Nöstlinger C, Loos J. Involving lay community researchers in epidemiological research: experiences from a seroprevalence study among sub-Saharan African migrants. AIDS Care. 2016;28(Suppl 1):119-23. https:// doi.org/10.1080/09540121.2016.1146398.

17. Chan KF, Lau T. Assessing technology incubator programs in the science park: the good, the bad and the ugly. Technovation. 2005;25(10):1215-28. https://doi.org/10.1016/J.TECHNOVATION.2004.03.010.

18. Harper-Anderson E, Lewis DA. What makes business incubation work? Measuring the influence of incubator quality and regional capacity on incubator outcomes. Econ Dev Q. 2018;32(1):60-77. https://doi.org/10.1177/ 0891242417741961.

19. Cornelius B, Bhabra-Remedios R. Cracks in the egg: improving performance measures in business incubator research. Fac Commer Pap. 2003; http://ro. uow.edu.au/commpapers/2875. Accessed 7 June 2017.

20. Bergek A, Norrman C. Incubator best practice: A framework. Technovation. 2008;28(1):20-8. https://doi.org/10.1016/j.technovation.2007.07.008.

21. Rothschild L, Darr A. Technological incubators and the social construction of innovation networks: an Israeli case study. Technovation. 2005;25(1):5967. https://doi.org/10.1016/S0166-4972(03)00064-6.

22. Avni S, Averbuch E. Health Inequity; 2016

23. Muhsen K, Green MS. Health in Israel 3 Inequalities in non-communicable diseases between the major population groups in Israel: achievements and challenges. Lancet. 2017;389. https://doi.org/10.1016/50140-6736(17)30574-3.

24. CBS. Characterization and Classification of Geographical Units by the SocioEconomic Level of the Population 2008. Jerusalem: Israeli Central Bureau of Statistics; 2013.

25. King $G$, Servais $M$, Kertoy $M$, et al. A measure of community members' perceptions of the impacts of research partnerships in health and social services. Eval Program Plan. 2009;32(3):289-99. https://doi.org/10.1016/j. eval progplan.2009.02.002

26. Sandelowski M. Member check. In: Given L, editor. The Sage Encyclopedia of Qualitative Research Methods. Thousand Oaks: SAGE Publications; 2008.

27. Nicolopoulou K, Karataş-Özkan M, Vas C, Nouman M. An incubation perspective on social innovation: the London hub - a social incubator. R D Manag. 2017;47(3):368-84. https://doi.org/10.1111/radm.12179.

28. Wallerstein N, Duran B. Community-based participatory research contributions to intervention research: the intersection of science and practice to improve health equity. Am J Public Health. 2010;100(Suppl 1): S40-6. https://doi.org/10.2105/AJPH.2009.184036.

\section{Publisher's Note}

Springer Nature remains neutral with regard to jurisdictional claims in published maps and institutional affiliations.

Ready to submit your research? Choose BMC and benefit from:
- fast, convenient online submission
- thorough peer review by experienced researchers in your field
- rapid publication on acceptance
- support for research data, including large and complex data types
- gold Open Access which fosters wider collaboration and increased citations
- maximum visibility for your research: over 100M website views per year
At BMC, research is always in progress.
Learn more biomedcentral.com/submissions

